\title{
La Función de la Naturaleza en Canciones para cantar en las barcas
}

$\mathrm{E}^{\mathrm{s}}$ I segundo libro de poesía escrito por José Gorostiza - Muerte sin fin- ha suscitado bastante interés entre los críticos, sin duda a causa de su complejidad, derivada del sentido filosófico de este poema. ${ }^{1}$ Pero casi nadie ha estudiado detenidamente un anterior libro de Gorostiza, publicado en 1925 con el título de Canciones para cantar en las barcas. ${ }^{2}$ La aparente sencillez de éste y su uso de imágenes claras tal vez haya llevado a los críticos a considerarlo como "poesía fácil, de tono menor," en palabras de Jorge Carrera Andrade. 3 Pero si examinamos con cuidado los poemas de Canciones, veremos que tras su forma sencilla se esconden los mismos profundos problemas que motivaron Muerte sin fin.

El libro contiene veinticinco poesías, reunidas en tres secciones. En casi todos los poemas observamos el empleo de imágenes que se refieren a la naturaleza, sobre todo a la naturaleza marina; ésta parece consti-

1 Muerte sin fin se publicó por primera vez en 1939 (México: Ediciones R. Loera y Chávez); $2^{a}$ ed. en 1952 , por la Imprenta Universitaria, con un "Comentario al poema" de Octavio Paz. Además de este comentario, fechado en 1951 y reimpreso como "Muerte sin fin" en el libro de Paz, Las peras del olmo (México: Imprenta Universitaria, 1957), pp. 105-114, se han publicado últimamente los siguientes estudios: Ramón Xirau, "Descarnada lección de poesía," Tres poetas de la soledad (México: Antigua Librería Robredo, 1955), pp. 13-20; Manuel Ponce, "Dios y el poeta," Abside, XIX (1955), 330-331; Emma Godoy, "Muerte sin fin de Gorostiza," Abside, XXIII (1959), 125-180; Aurelio Espinosa Pólit y Emma Godoy, "Al filo de Muerte sin fin," Abside, XXIII (1959), 452-459; y Frank Dauster, "Notas sobre Muerte sin fin," Revista Iberoamericana, XXV, No. 50 (1960), 273-288.

2 Canciones para cantar en las barcas fue publicado por Ia Editorial Cultura, en México en 1925.

3 Jorge Carrera Andrade, "México en dos dimensiones," La voz (Nueva York), II (febrero 1959), 21. De manera parecida, Arturo Torres-Rioseco ve simplicidad y falta de vigor en la poesía de Gorostiza. Véase su La poesía lírica mexicana (Santiago de Chile: Imprenta Universitaria, 1933), p. 35. 
tuir el asunto principal de Canciones. Pero un análisis cuidadoso de la obra nos permite concluir que lo natural no se utiliza como un fin en sí mismo, sino más bien como un vehículo para expresar significados humanos. Para demostrar esto, veamos varios poemas de Canciones para cantar en las barcas.

En muchas poesías, los elementos de la naturaleza se evocan para crear una impresión, un ambiente afectivo que sirve para producir un estado de ánimo humano. Una de estas obras, "Se alegra el mar," nos recuerda la poesía tradicional española:

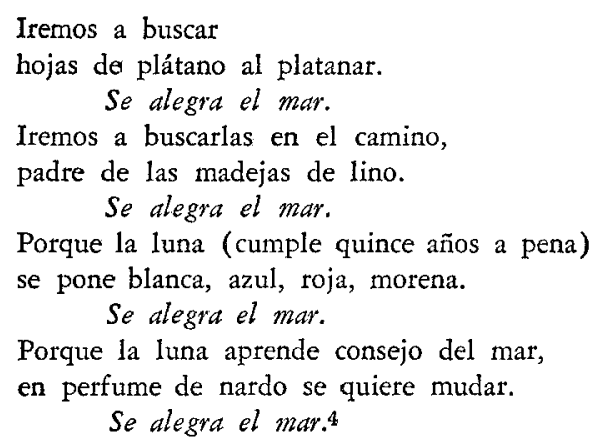

La primera mitad del poema nos describe elementos naturales como si fueran seres humanos; el mar y la luna sienten emociones humanas y actúan como personas (el mar es sabio consejero, la luna niña ingenua). La imagen del camino como "padre de las madejas de lino" se basa sobre un parecido visual, pero sirve para unir un producto humano con un objeto de la naturaleza, que también queda personificado.

Siete varas de nardo desprenderé para mi novia de lindo pie.

Se alegra el mar.

Siete varas de nardo: sólo un aroma, una sola blancura de pie de paloma.

Se alegra el mar.

Vida - le digo- blancas las desprendí, yo bien lo sé, para mi novia de lindo pie.

Se alegra el mar.

4. José Gorostiza, Canciones para cantar en las barcas, p. 13. De aquí en adelante nos referiremos al libro escribiendo solamente Canciones. 
Vida -le digo- blancas las desprendí, ¡no se vuelvan oscuras por ser de mí!

Se alegra el mar.5

La segunda parte de la misma obra trata del protagonista. Éste recoge varas de nardo para of recérselas a su amada, con la esperanza de que la blanca flor no se vuelva oscura. Aunque no se puede discernir aquí un simbolisma obvio, la blancura de la flor sin duda sugiere el amor o la felicidad, mientras que su transformación en algo oscuro representaría alguna desgracia. Por medio de los colores de una flor, el protagonista hace concreta su búsqueda del amor y de la felicidad, así como sus deseos de salvarse del fracaso. La naturaleza, que había sido humanizada en la primera parte del poema, ahora sirve a su vez para expresar las emociones de una persona. "Se alegra el mar" constituye una unidad total, dentro de la cual la primera parte nos prepara para el valor humano de la segunda. Pero conviene observar que el poema carece de un esquema rígido o simbólico; la obra está compuesta de metáforas y personificaciones que crean una impresión general, y sugieren, en último análisis, un sentido humano. Esta técnica deja el poema abierto a inferencias más amplias y universales.

En la sección de libro titulada "Dibujos sobre un puerto" encontramos varias poesías cortas; la mayoría de éstas consisten de una sola imagen. Antonio Castro Leal ha comentado que estas obritas se parecen a los baikai japoneses, diminutos poemas que presentan cuadros de la naturaleza con gran esmero formal. ${ }^{6}$ Nosotros no estamos de acuerdo: las representaciones de la naturaleza no tienen aquí un fin puramente pictórico ni objetivo, sino que sirven para comunicarnos algo acerca de las emociones básicas del hombre. Esta cualidad es precisamente la que, según el crítico Daniel Castañeda, define a la copla española y la contrasta con el baikai. Gorostiza se sitúa, por lo tanto, en la corriente de la poesía tradicional, y no de la japonesa.

5 Ibid., p. 13.

6 Antonio Castro Leal, La poesía mexicana moderna [Conferencia ante la Academia Mexicana de la Lengua] (México: Academia Mexicana de la Lengua, $1953)$, p. 27. Véase también Xavier Villaurrutia, La poesía de los jóvenes de México (México: Ediciones de la Revista Atenea, 1924), p. 14; y Alfonso Méndez Plancarte, "Primor y primavera del 'hai-kai'," Abside, XXV (1950), 495-531.

7 Daniel Castañeda, "Entre el haikai y la copla," Letras de México, Año IX, I (15 de mayo de 1943), 4; Castañeda observa que los baikai, a diferencia de las coplas, nunca fueron cantados. Al llamar su libro Canciones, Gorostiza parece estar pensando en las coplas. 
Examinemos primero el poemita "Cantarcillo":
Salen las barcas al amanecer.
No se dejan amar, pues suelen no volver
o sólo regresan a descansar. 8

Las barcas aparecen como mujeres capaces de ser amadas; la humanización se subraya en el último verso, cuando la vuelta al puerto se describe como un descanso. Las acciones de "amar" y "descansat" se unen por la rima consonante que liga estas palabras. Todo esto da valor humano a la escena: pensamos en mujeres que huyen del amor (salida de las barcas) y esquivan una vida estable (regreso transitorio). Las barcas han servido para expresar de manera muy concreta unas emociones femeninas.

"Oración" logra efectos parecidos:

La barca morena de un pescador, cansada de bogar, sobre la playa se puso a rezar:

¡Házme, Señor, un puerto a las orillas de este mar!9

La barca se personifica por medio de su cansancio y de su oración. E1 adjetivo "morena," además, nos hace pensar tal vez en una mujer hermosa (lo que no haría "parda" u "oscura"). Su anhelo de un puerto, entonces, nos hace sentir el deseo humano de alcanzar un lugar de descanso.

Como otros poemas de Canciones, los tres que acabamos de estudiar nos comunican emociones fundamentalmente humanas a través de impresiones naturales; ${ }^{10}$ como la poesía tradicional, esconden un valor especial bajo su apariencia sencilla.

En otros poemas de Canciones, encontramos no sólo conjuntos de impresiones como las que hemos visto hasta ahora, sino sistemas más organizados de imágenes. Una técnica empleada varias veces es la que el crítico Carlos Bousoño denominó la de "signos de sugestión." 11 Se

8 Gorostiza, Canciones, p. 49.

9 Ibid., p. 51.

10 Véanse los poemas "Luciérnagas" (Canciones, pp. 53-54) y "Mujeres" (Ibid., pp. 29-30).

11 Carlos Bousoño, Teoría de la expresión poética (Madrid: Editorial Gredos, 1956 [2 $2^{\text {a }}$ ed.]), pp. 120-124. 
trata de palabras, imágenes o escenas repetidas a través de un poema que, sin ser símbolos que representen siempre el mismo significado conceptual, comunican claramente el mismo sentido afectivo cada vez que aparecen.

Un buen ejemplo de esta técnica es "El enfermo." Este poema nos presenta alternativamente dos escenas que se contrastan: el cuarto de un moribundo y un jardín provisto de una fuente y de un pájaro que canta:

$$
\begin{aligned}
& \text { Por el amplio silencio del instante } \\
& \text { pasa un vago temor. } \\
& \text { Tal vez gira la puerta sin motivo } \\
& \text { y se recoge una visión distante, } \\
& \text { como si el alma fuese un mirador. } \\
& \text { Afuera canta un pájaro cautivo, } \\
& \text { y con gota fugaz el surtidor. } \\
& \text {........................ }
\end{aligned}
$$

Sin hacer que ninguno de los objetos descritos represente una idea abstracta, Gorostiza luego contrapone la fugacidad de la vida del hombre a la duración de los elementos naturales del jardín: el enfermo muere al final de la poesía, mientras que el jardín continúa como al principio:

$$
\begin{aligned}
& \text { Tal vez gira la puerta sin motivo. } \\
& \text { Afuera canta un pájaro cautivo, } \\
& \text { y con gota fugaz el surtidor.13 }
\end{aligned}
$$

El pájaro y la fuente son signos que el lector identifica con la permanencia del paisaje.

Aquí Gorostiza nos da también una explicación más amplia de su propósito. En "El enfermo," la naturaleza posce valores eternos que le han sido negados al hombre; representa, por lo tanto, una posible solución al problema del ser humano. Si éste puede de alguna manera identificarse con lo natural y transmitirle sus emociones y sus valores, habrá eternizado algo suyo, y alcanzado una forma de la permanencia que le falta.

Esta explicación ayuda a justificar el énfasis puesto en la naturaleza que hemos estado observando en los poemas de Gorostiza. Ahora

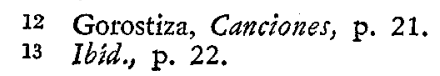


empezamos a comprender que el poeta utiliza la naturaleza como vehículo para dar permanencia a los problemas humanos que quiere presentarnos. Al verter sus significados en imágenes naturales, los libra de las limitaciones de su época, y los hace asequibles al lector de cualquier tiempo futuro.

Recordando todo esto, pasemos a examinar "Acuario," una poesía que trata de Jenny Lind, cantante del siglo diecinueve.14 Los primeros versos la sitúan en el pasado:

Los peces de colores juegan

donde cantaba Jenny Lind.15

Inmediatamente se establece un contraste entre Jenny y la naturaleza; mientras que la mujer ha desaparecido, los peces quedan. Pero en seguida la joven misma aparece presentada por medio de un elemento natural:

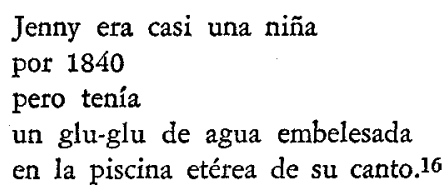

La imagen de la voz como piscina nos recuerda los peces; otra vez, un objeto permanente de la naturaleza sugiere la temporalidad de Jenny. Pero por otra parte, esta metáfora del agua también describe el canto de la joven, y en este sentido la hace vivir para nosotros. Al ver su cantar como "agua embelesada," el lector de cualquier siglo podrá apreciar su belleza. En última instancia, la imagen natural universaliza a un ser humano.

La naturaleza sirve, igualmente, para hacernos sentir el ambiente en que Jenny vivía:

New York era pequeño entonces.

Las casitas de cuatro pisos

debían de secar la ropa

recién lavada

14 Jenny Lind (1820-1887.), considerada por algunos como la mejor soprano de cualquier época, era una cantante sueca que viajó por los Estados Unidos, en un recorrido arreglado por $P$. T. Barnum, entre 1850 y 1852 . Véase la $\mathrm{Co}_{0}$ lumbia-Viking Desk Encyclopedia (New York: Viking Press, 1953).

15 Gorostiza, Canciones, p. 39.

16 Ibid., p. 39. 


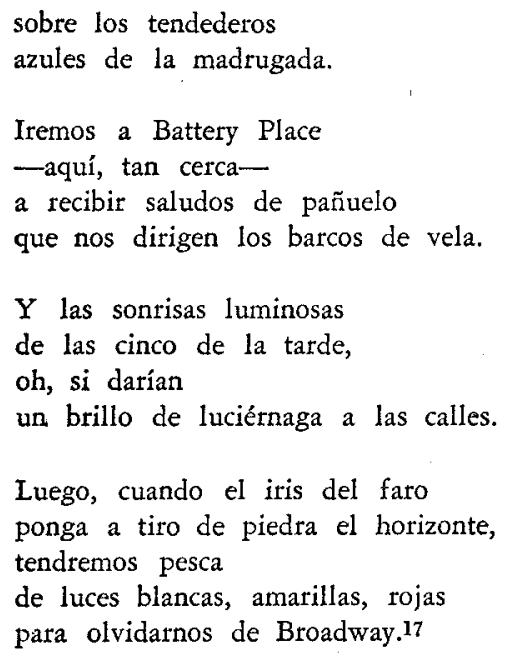

Los objetos descritos nos of recen una atmósfera más bien que un cuadro exacto. El ambiente es íntimo, y se logra a través de la humanización de varios objetos. Las casas se personifican como dueñas de la ropa que se seca, los barcos al agitar pañuelos, la luz de la tarde al sonreír. En cada caso, el autor hábilmente revela un significado emocional mediante una imagen visual, sin dejar de ser fiel a la realidad. ( $i$ Las velas de los barcos se parecen, en efecto, a pañuelos agitados a lo lejos!) El efecto es el de convertir la Nueva York del siglo diecinueve en algo íntimamente cercano al lector. La pequeñez de la ciudad ya no tiene valor exacto y geográfico, sino que sirve más bien para evocar una realidad humana y afectiva. La ciudad, sus habitantes y Jenny Lind son tan traviesamente vivos que están a punto de hacernos olvidar el presente ("Broadway"). Aunque pertenecen al pasado, han sido captados para siempre en el poema.

Porque Jenny Lind era como el agua reída de burbujas en que los peces de colores juegan.18

"Acuario" acaba con la misma escena con que empezó, pero esta vez con un sentido diferente. La imagen de los peces, que antes parecía

17 Ibid., pp. 39-40.

18 Ibid., p. 40. 
separar a Jenny del tiempo presente, ahora la une con éste. El símil visual, como las otras imágenes, insinúa un significado emocional: las burbujas del "agua reída" nos hacen pensar en la alegría característica de la cantante. Al relacionar a Jenny Lind con un objeto natural, la estrofa recuerda de nuevo el valor que tiene la naturaleza para encarnar atributos humanos.

La serie de imágenes naturales, así humanizadas, forma en "Acuario" un grupo de "signos de sugestión"; todas juntas combinan para dar realidad emocional a un pasado humano, y asi salvarlo de ser olvidado. Este poema, igual que "El enfermo," comienza contrastando la permanencia de la naturaleza con la impermanencia del hombre; habiendo hecho esto, emplea una visión de la naturaleza para eternizar al hombre y sus circunstancias.

Los "signos de sugestión" se emplean en "Acuario" para presentar un cuadro de la naturaleza con mayor exactitud que el impresionismo algo difuso de "Se alegra el mar"; la Nueva York tan íntima nos proporciona una unidad concreta que da realidad a Jenny y su época. Esta técnica, entonces, le permite a Gorostiza lograr claridad sin sucumbir a la excesiva rigidez. Xavier Villaurrutia ya observó esta cualidad de su obra cuando escribió: "Los motivos de su arte tenían que ser dibujados y al mismo tiempo transparentes." 19

Hasta ahora hemos examinado poesías que utilizan aspectos de la naturaleza de modo metafórico. En otras palabras, los objetos del mundo natural funcionan para ampliar el sentido lógico y afectivo que el poeta quiere comunicarnos. (Los "signos de sugestión" son simplemente un sistema organizado de símiles y metáforas.)

Además de lo antedicho, Gorostiza emplea la naturaleza como símbolo. Cuando lo hace, el objeto natural no sólo se compara con otra cosa para ampliar el significado de ésta, sino que funciona como sustituto de otro objeto o pensamiento, representándolo e identificándose completamente con él a través del poema. ${ }^{20} \mathrm{~A}$ causa de esta equivalencia completa, el uso de símbolos tiende a producir significados rígidos y unilaterales.

19 Xavier Villaurrutia, "Un poeta" [fechado en 1926], Textos y pretextos; literatura, drama, pintura (México: La Casa de España en México, 1940), p. 82. Observamos que el "signo de sugestión", por lo tanto, parece otorgar algo de la precisión del símbolo a una presentación metafórica, pero sin añadir sentidos ideológicos.

${ }_{20}$ Véase Cleanth Brooks y Robert Penn Warren, Understanding Poetry (New York: Henry Holt and Co., 1950 [ed. revisada]), pp. 687-689. 
El poema "La orilla del mar" empieza describiendo un sitio:

$$
\begin{aligned}
& \text { No es agua ni arena } \\
& \text { la orilla del mar. } \\
& \text { El agua sonora } \\
& \text { de espuma sencilla, } \\
& \text { el agua no puede } \\
& \text { formarse la orilla. } \\
& \text { Y porque descanse } \\
& \text { en muelle lugar, } \\
& \text { no es agua ni atena } \\
& \text { la orilla del mar.1 }
\end{aligned}
$$

La primera estrofa presenta la idea, que luego queda explicada en más detalle. La orilla es algo abstracto: un punto de contacto entre dos materias, que no pertenece por completo a ninguna de las dos. La segunda estrofa muestra la limitación del agua, la tercera la de la arena. Al humanizar el agua, el poema nos hace sentir su falta como la de una persona, añadiendo un toque emotivo e insinuando el problema humano que aparecerá más tarde en el poema. Todo este tema es muy sugeridor: en medio de la realidad más material encontramos una abstracción que resulta de la unión de dos objetos, pero que no puede presentarse en términos materiales. Esta escena nos hace darnos cuenta de que hay en el mundo un elemento - la unión- que no podemos explicar materialmente.

$$
\begin{aligned}
& \text { Las cosas discretas, } \\
& \text { amables, sencillas; } \\
& \text { las cosas se juntan } \\
& \text { como las orillas. } \\
& \text { Lo mismo los labios } \\
& \text { si quieren besar. } \\
& \text { No es agua ni arena } \\
& \text { la orilla del mar.22 }
\end{aligned}
$$

El resto de la obra amplía el problema a base de la imagen inicial. El personificar las "cosas" ("discretas, amables, sencillas") las acerca a l hombre; entonces el poema pasa fácilmente a un tema humano, y des-

21 Gorostiza, Canciones, p. 11.

22 Ibíd., p. 12. 
cribe el beso como una unión paralela a la orilla. Al enlazar así los dos mundos -el natural y el humano-, sitúa el amor dentro del esquema general de la vida. Y luego, al repetir los dos versos iniciales, identifica la imagen de la orilla como símbolo de todo el misterio de la unión en las cosas y en los seres.

$$
\begin{aligned}
& \text { Yo solo me miro } \\
& \text { por cosa de muerto } \\
& \text { solo, desolado, } \\
& \text { como en un desierto. } \\
& \text { A mí venga el lloro, } \\
& \text { pues debo penar. } \\
& \text { No es agua ni arena } \\
& \text { la orilla del mar. }{ }^{23}
\end{aligned}
$$

El misterio se convierte ahora en problema subjetivo: el protagonista declara su soledad y sufrimiento. Pero en virtud de lo que hemos visto antes, este episodio cobra un valor más profundo. Sentimos que el hombre no puede lograr, por sí solo, el ideal impalpable de la unión con otro ser. Sólo le es dado sufrir y llorar. La repetición de los versos iniciales subraya el entronque entre el apuro de este hombre y el tema general de la inexplicabilidad de las correspondencias.

En "La orilla del mar," el símbolo de la orilla contiene en sí todo el significado del poema; la obra resulta directa, enérgica, concisa. $Y$ al enfocar una sola escena visual, adquiere una realidad asombrosa. La exactitud del procedimiento simbólico le ha permitido a Gorostiza captar clara y unidamente un tema tan abstracto.

Otro símbolo natural aparece en "¿Quién me compra una naranja?":

$$
\begin{aligned}
& \text { ¿Quién me compra una naranja } \\
& \text { para mi consolación? } \\
& \text { Una naranja madura } \\
& \text { en forma de corazón. } \\
& \text { La sal del mar en los labios } \\
& \text { jay de mí! } \\
& \text { la sal del mar en las venas } \\
& \text { y en los labios recogí. }
\end{aligned}
$$

Nadie me diera los suyos

para besar.

23 lbid., p. 12. 


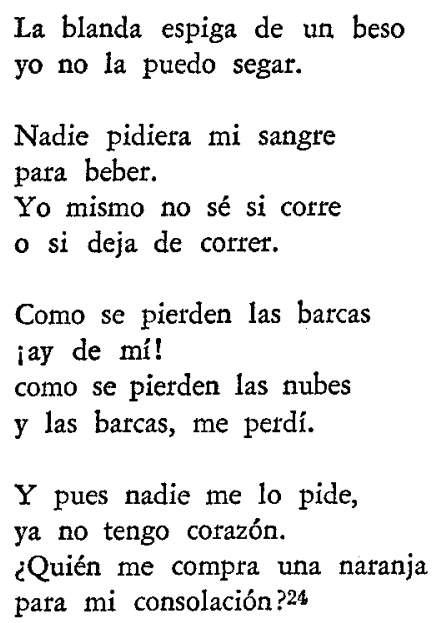

La primera estrofa identifica la naranja como un objeto natural correspondiente a nuestro corazón, y subraya a la vez el parecido visual. El poema entonces evoca la situación del protagonista: el hombre sufre a causa de su soledad y su falta de alguien que lo ame. Las imágenes nos revelan el significado que se oculta tras este cuadro. El apuro del protagonista se presenta por medio de objetos de la naturaleza - la sal nos hace sentir su sufrimiento, la falta de la espiga (que sugiere cosecha, realización) representa la falta de un beso. Esto tiene un doble efecto: la emoción humana se nos hace al mismo tiempo más concreta y menos anecdótica. La soledad y la falta de amor ya no son sólo la pena de un protagonista específico, sino parte del proceso del mundo natural.

En la cuarta estrofa, el hombre ya no está ni siquiera seguro del correr de su sangre, ya que nadie la desea. Si vemos la sangre como una imagen que representa todo su ser, entenderemos la razón del dolor. El protagonista nos está diciendo que para asegurarse de la existencia de uno, hay que ser amado por alguien fuera de sí; él mismo se ha perdido por falta de tal amor. Al compararse con objetos naturales que se pierden fácilmente (las nubes y las barcas), este personaje nos recuerda de nuevo que él está expresando un tema general.

La última estrofa resume la situación con finalidad, y acaba con la repetición de los primeros versos. Sólo que la naranja, antes comparada a un corazón, se ha convertido en un sustituto - símbolo- del corạ-

24 Ibid., pp. 9-10. 
zón y del amor que le faltan al protagonista. Al simbolizar el apuro de éste por medio de un objeto natural, Gorostiza nos hace olvidar completamente el episodio particular, y subraya el aspecto cósmico del tema.

En varios otros poemas encontraremos el uso de la naturaleza como símbolo. En "Borrasca," por ejemplo, la muerte se representa por medio de una tempestad:

\section{Cuando llegue el minuto negro de mi borrasca, hazme sufrirlo aquí, junto a la orilla del agua amarga.25}

Esto no sólo vivifica la muerte, sino que también la relaciona con la destrucción natural causada por la tempestad, haciéndonos ver nuestro fin como parte de la ley natural del mundo. En "Nocturno," por otro parte, donde la muerte se representa con más calma, queda simbolizado por un viajero, y vista de manera más anecdótica:

esta noche sin luces aguardo ante mi puerta
los tres toques de aldaba que tocatá un viajero. 26

El ambiente nocturno es el mismo, pero el uso de un símbolo diferente le da otro tono al problema, indicando que Gorostiza emplea los símbolos no como código inflexible, sino más bien como vehículo de comu. nicación que se adapta a la emoción o al significado particular. Aunque añaden exactitud al poema, no lo despojan de su valor afectivo.

Gorostiza emplea la naturaleza como base de comparación (metáfora, símil, "signo de sugestión") al explorar emociones y temas humanos fácilmente comprendidos por el lector (como el amor, el pasar del tiempo, etc.). Así les infunde realidad y permanencia, sin limitar la extensión de significados que pudieran sugerir. Pero cuando se trata de un asunto más abstracto, como la soledad o la muerte, recurre a la exactitud del símbolo. En cada caso utiliza la naturaleza del modo más precisamente adecuado a las circunstancias dadas.

Habiendo estudiado los diversos papeles que juega la naturaleza en Canciones para cantar en las barcas, podemos ver claramente que el mun-

\footnotetext{
25 Ibid., p. 32.

26 Ibid., p. 25.
} 
do natural sirve siempre como manera de hacer concretas emociones y situaciones humanas - -sea por medio de impresiones, de "signos de sugestión", o de símbolos. El modo en que lo natural universaliza los valores humanos es de suma importancia. Cuando hablamos de "El enfermo", ya indicamos que el poeta, al situar sus significados en el mundo permanente de la naturaleza, los salva de la destrucción causada por el tiempo y por la muerte. Las imágenes naturales que aparecen en el poema comunicarán su verdad mucho después de que el poeta haya muerto; si el escritor logra infundirles un sentido (conceptual, emotivo y sensorial), entonces por lo menos parte de este sentido se habrá salvado para el lector de otra época.

La obra en prosa de Gorostiza corrobora nuestra explicación. En 1928, nuestro escritor define la naturaleza empleada por el arte como: "naturaleza muerta, que el artista mata para hacerle vivir la duración de su muerte." 27 Para universalizar la naturaleza, el artista debe de esquivar la imitación mecánica, y tratar más bien de lograr un acto de creación, infundiéndole su propio significado a la materia. Entonces ésta de veras hará eterna su creación, mientras la creación renueva, a su vez, la naturaleza, dándole un nuevo sentido. La preocupación de Gorostiza por la función universalizadora del arte se puede comprobar también al examinar sus otros escritos críticos. ${ }^{28}$ Las teorías del autor confirman su propósito creador; sin duda alguna, Gorostiza se nos muestra como poeta de problemas humanos universalizados a través de la naturaleza, y no como versificador paisajista. ${ }^{29}$

\section{ANDREW P. Debicki}

Grinnell College, lowa

27 José Gorostiza, "De la pintura nueva," Universidad (México), V (febrero 1928 ), 32 .

28 Véase Andrew P. Debicki, "Sobre la poética y la crítica literaria de José Gorostiza," Revista Iberoamericana, XXVI, No. 51 (1961), 147-154.

29 Varios críticos observaron el valor de Canciones y su telación con el resto de la obra de Gorostiza, aunque desafortunadamente no hicieron un análisis detallado del libro. En particular debemos destacar a Octavio Paz, quien comentó: "La poesía juvenil de Gorostiza no es menos compleja que la de su madurez." Paz, "Muerte sin fin," Las peras del olmo, p. 108. También véase Xavier Villaurrutia, "Un poeta," pp. 78-83; Frank Dauster, "Notas sobre Muerte sin fin," P. 274; y Enrique Anderson Imbert, Historia de la literatura bispanoamericana (México: Fondo de Cultura Económica, 1954 [primera edición]), p. 337. 
